\title{
Study of the Effect of Nitrate and Sulfate Solutions on the Properties of Copper Nanopowder Synthesized by Electrochemical Method
}

\author{
Hind Al-Darkazali*, Riyadh M. Noaman, Muthana Mahmmod, Raad Acopy, Akram Dawood \\ Chemical and Petrochemical Research Center/ Corporation for Research and Industrial Development - Iraq
}

\author{
Article information \\ Article history: \\ Received: October, 01, 2021 \\ Accepted: October, 16, 2021 \\ Available online: October, 20, 2021
}

Keywords:

Nanocopper powder,

Electrolysis method,

Copper sulfate,

Copper nitrate

*Corresponding Author:

Hind Al-Darkazali

hind332000@gmail.com

DOI:

https://doi.org/10.53523/ijoirVol8I2ID93

\begin{abstract}
The electrochemical method is efficient, cost effective, and environmentally friendly process. Copper nanopowder has been known, as a nontoxic, inexpensive, highly conductive, excellent microbial agent, catalytic, and sensors applicable. Copper nanopowder was prepared by an electrochemical method under various conditions. The effect of type and concentration of electrolyte solution, and the sample treated with thiourea and ascorbic acid on the size and purity of copper nanopowder was investigated. Two different salts copper: sulfate and nitrate aqueous solutions $\left(\mathrm{CuSO}_{4} .5 \mathrm{H}_{2} \mathrm{O}\right), \mathrm{Cu}\left(\mathrm{NO}_{3}\right)_{2} .5 \mathrm{H}_{2} \mathrm{O}$ were used to produce copper nanopowder. The synthesized copper nanopowder was identified using X-ray diffraction (XRD), the scanning electron microscope (SEM), and Energy Dispersive Spectrum (EDS). The results of XRD patterns revealed a high degree of crystallinity, monophasic nature, and pure copper powder with no impurities or oxides observed for both electrolyte solutions after treated with 2 percent of ascorbic acid. It was confirmed that particle size at room temperature was as small as $25 \mathrm{~nm}$ when the copper nitrate is used as an electrolyte solution compared to copper sulfate $(41 \mathrm{~nm})$.
\end{abstract}

\section{Introduction}

The synthesis of metal Nanopowders has being given considerable attention due to their unique physical and chemical properties. Nanoparticles possess a high surface-to-volume ratio owing to their small size. This feature has attracted many researchers to widely investigate nanomaterials and their applications. Metallic nanoparticles have been vastly used for numerous applications, such as catalysis, solar energy, optical, magnetic, thermal, biological sensors, synthesis of chemical composite, and medicine [1-3].

Several methods have been utilized to prepare the metallic Nanopowder, such as chemical, physical, and biological reduction methods. Each one of these synthesis methods has advantages and disadvantages in producing metallic nanopowder. The chosen synthesis method needs to consider numerous agents, some of them related to shape, size of the nanoparticles, and other concerns to cost, level of production, and hazard. Electrochemical deposition technique is among the most important appropriate, simple, fast, high throughput, and economical methods which are used for a diversity of materials including copper nanopowder[4, 5].

This method is relatively clean, non-toxic, environmentally friendly, and it can be done under room temperature using copper salts as an electrolytic solution. The problem that still occurs in synthesis with electrochemistry is 
the existence of ionic interactions and nonuniform splits for the grains particle size. Many parameters have an effect on the morphology of copper nanopowder, such as overvoltage, level of released hydrogen, current density, concentration of copper ion, $\mathrm{pH}$, temperature, distance and materials of electrodes, etc. [4].

Copper nanopowder has excellent electrical and thermal properties make it an important in many industrial applications such as photochemical catalysis, biosensing, gas sensor, electrochemical sensing and solar/photovoltaic energy conversion, lubrications, nanofluids, conductive films, conductive ink, \& conductive paste for printed electronics, and antimicrobial agents. Copper nanopowder showed antifungals and insecticidal activity against the pests of crop plants. It can be used as fertilizers, herbicides, and pesticides[6]. The copper nanoparticles are preferred in many applications compare with other metallic nanopowder such as gold and silver nanopowder owing to the cost effective and the physical and chemical stability [7-10].

In this work, we try to overcome the electrochemical method problems to produce homogenous pure copper nanopowder. The effect of type and concentrations of electrolyte solutions, current density, the addition of thiourea and ascorbic acid, on the size and purity of copper nanopowder was studied. Two different types of copper salts $\left(\mathrm{CuSO}_{4} .5 \mathrm{H}_{2} \mathrm{O}\right), \mathrm{Cu}\left(\mathrm{NO}_{3}\right) 2.5 \mathrm{H}_{2} \mathrm{O}$ were used to produce copper nanopowder. X-ray diffraction (XRD), scanning electron microscope (SEM), and Energy Dispersive Spectrum (EDS) were used to investigate the powder purity, shape, and particle size of synthesized copper nanopowder.

\section{Materials and Methods}

Two rods of $99.99 \%$ copper were used as the cathode and the anode. $\left(\mathrm{CuSO}_{4} \cdot 5 \mathrm{H}_{2} \mathrm{O}\right) \geq 98 \%,\left(\mathrm{Cu}\left(\mathrm{NO}_{3}\right)_{2} \cdot 5 \mathrm{H}_{2} \mathrm{O}\right) \geq$ $98 \%$, ascorbic acid, acetone, thiourea 99\%, ethanol was purchased from Sigma-Aldrich. $\mathrm{H}_{2} \mathrm{SO}_{4}$ was purchased from Merck.

\subsection{Synthesis of Copper Nanopowder \\ 2.1.1 The Electrochemical Cell}

Two cylindrical shape, with a length of $15 \mathrm{~cm}$ and a diameter of $2 \mathrm{~mm}$ of high purity copper (999.99\%) were used as the two electrodes in the cathodic electrochemical cell. The electrodes were washed with deionized water (DI) and polished with very fine sand paper (220 grit). Afterward, they were washed with DI water. After drying in ambient temperature, the wires promptly immersed in ten percent of $\mathrm{H}_{2} \mathrm{SO} 4$ bath for five minutes, then placed in the ultrasonic bath for five minutes to remove the surface oxide layer. The electrodes were washed out again with DI water and then placed into the electrolyte solution. Electrolysis was carried out at a temperature of 27.0 $\pm 0.5^{\circ} \mathrm{C}$ in an open cell of cylindrical shape. The rode of copper electrodes was positioned at a distance of about $2 \mathrm{~cm}$ from each other as shown in Figure (1) $[1,7]$.

\subsubsection{Electrolyte Solutions and Additives}

Two types of Electrolyte solutions were prepared using salts copper: sulfate $\left(\mathrm{CuSO}_{4} .5 \mathrm{H}_{2} \mathrm{O}\right)$ and nitrate, $\mathrm{Cu}\left(\mathrm{NO}_{3}\right)_{2} .5 \mathrm{H}_{2} \mathrm{O}$. Three concentrations of each salt were used $(0.1 \mathrm{M}, 0.5 \mathrm{M}$ and $1 \mathrm{M})$. Two types of antioxidants were added separately to the electrolyte solution in various concentrations, $0.02 \%$ thiourea and $2 \%$ Ascorbic acid. The synthesized nanopowder was collected from all experimental conditions for characterization.

Current densities of $0.8,1.5,2 \mathrm{~A} / \mathrm{cm}^{2}$ were used. The current was Reversed every two minutes. The precipitated copper nanopowder is deposited as a superfine coat powder on the surface of the cathode electrode. Each test was run for five hours. The precipitated copper nanopowder was separated from the electrolyte solution as shown in Figure (2) by centrifugation for 3 minutes at $13000 \mathrm{rpm}$, then washed with DI water for three times. A small amount of acetone was added to the powder, and then the samples dried out in the air atmosphere.

\subsection{Characterization}

In order to identify and confirm the purity, the powder was characterized by the X-ray diffraction (XRD), with a $\mathrm{Cu}-\mathrm{K} \alpha$ radiation using an Angstrom Advanced XRD model ADX2700 diffractometer (USA) equipped with a graphite monochromator and operated at $40 \mathrm{kV}$ accelerating voltage and $30 \mathrm{~mA}$ current. The test was performed using a stepscanning program with $0.05^{\circ}$ per step and acquisition time of 5 seconds per step at 2-theta and a scanning range of $10-90^{\circ}$. The XRD data were analyzed using jade 6.5 , which contains the information of the Committee for Powder Diffraction Standards (JCPDS). The surface morphological and purity characterization is done using scanning electron microscopy (SEM) type FEI INSPECT S50. 


\section{Results and Discussion}

Electrochemical deposition is a trustworthy method for many reasons; it is simple, economic, highly productive, and eco-friendly. However, a variety of problems are associated with this method, such as producing undesirable ions, besides that there is an issue of producing samples with different shape and size. The power supply provides a constant current to one of the two electrodes pushing the positive ions to pass through the electrolyte solution to the second electrode. During this process, chemical changes will occur. The dissociation process of the electrolyte and dissociated ions could be shown at the electrodes. Three different current densities $(0.8,1.5,2$ $\mathrm{A} / \mathrm{cm}^{2}$ ) were used. However, the rise of the current density led to an increase in the size of copper powder which reaches to micrometre in size (data are not shown here). The releasing process of copper nanoparticles from one electrode to the second could happen too. The copper nanoparticle was removed by reversing current flow for two minutes manually. The deposited copper nanoparticles were collected by centrifuging the sample at 13000 rpm for three minutes and washed several times with distilled water to remove the impurities. A small amount of acetone was added to prevent oxidation. The sample then dried out in the air atmosphere [5].

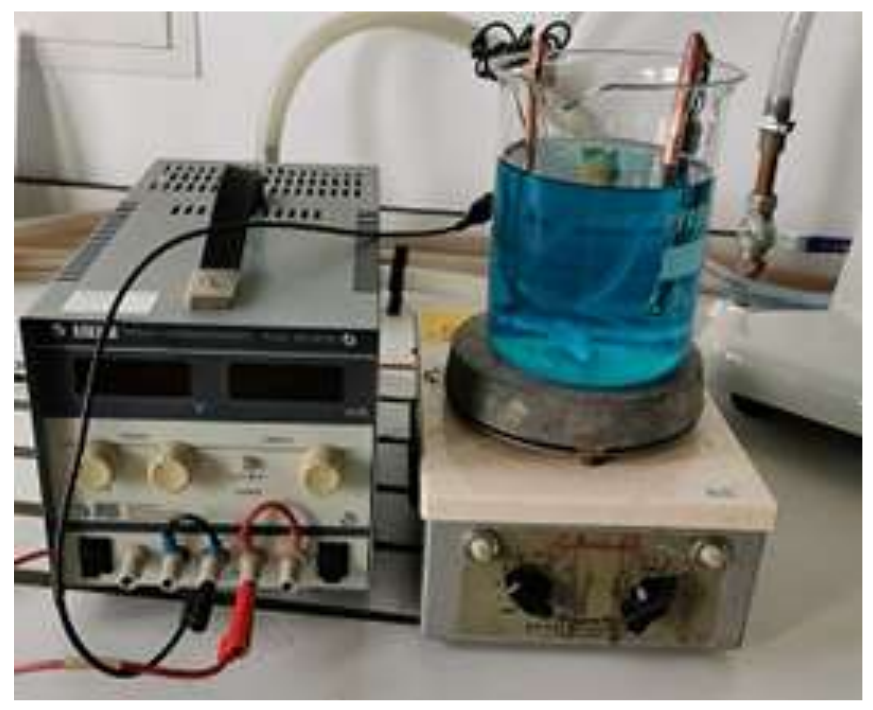

Figure (1). Electrochemical cell.

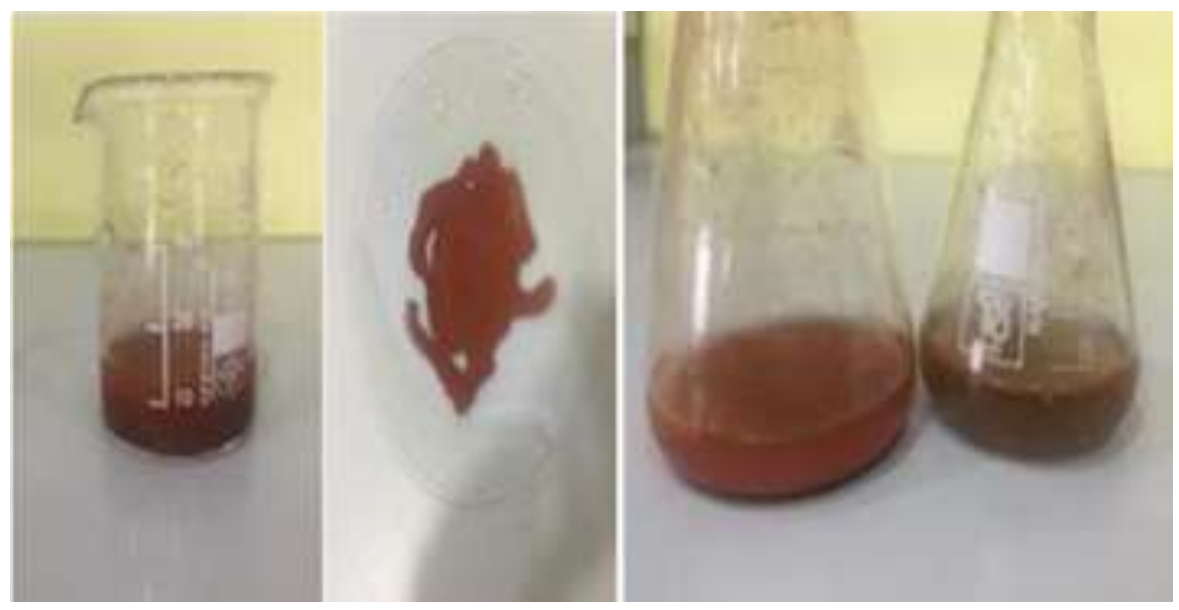

Figure (2). Synthesized Copper Nanopowder.

X-ray diffraction is a Powerful and rapid characterization technique used in solid-state materials. The pattern of diffraction provides information on the shape and size of the unit cell and the information of electron density inside the unit cell and peak positions, specifically where the atoms are located from peak intensities [11]. The 
indexing procedure of powder diffraction pattern was achieved and Miller Indices (hkl) for all peaks were assigned. Jade 6.5 software was used to estimate the average particle size, which is calculated from DebyeScherrer formula. X-Ray Diffraction was achieved to describe the effect of electrolyte solutions and their additives on particles crystallinity and the purity of copper nanopowder comparing with the standard ICDD card. Different concentrations of copper sulphate were used $(0.1,0.5$ and $1 \mathrm{M})$. The results of XRD show that the low concentration of $\mathrm{CuSO}_{4} .5 \mathrm{H}_{2} \mathrm{O}$ leads to an increase in $\mathrm{Cu}$ nanopowder oxidation and almost the participated powder was copper oxide as shown in Figure (3). The $2 \theta$ of 29.381, 36.26, 42.139, 52.295, 61.221, 69.357, 73.417, and $77.239^{\circ}$ correspond to (110), (111), (200), (211), (220), (310), (311) and (222) crystal planes of $\mathrm{Cu}_{2} \mathrm{O}$. However, the nanopwoder with $1 \mathrm{M}$ concentration is showing a mix of nanocopper and nanocopper oxide as exhibited in Figure (4), and the size of the crystals is $41 \mathrm{~nm}$. The $2 \theta$ of 29.279, 36.199, 42.041, 52.312, $61.160,73.380$, and $77.219^{\circ}$ correspond to (110), (111), (200), (211), (220), (311), and (222) crystal planes of $\mathrm{Cu}_{2} \mathrm{O}$ and $43.119,50.398^{\circ}$, and $73.899^{\circ}$ correspond to (111), (200), and (220) crystal planes of $\mathrm{Cu}$, which confirm face centred cubic (FCC) crystal lattice of both.

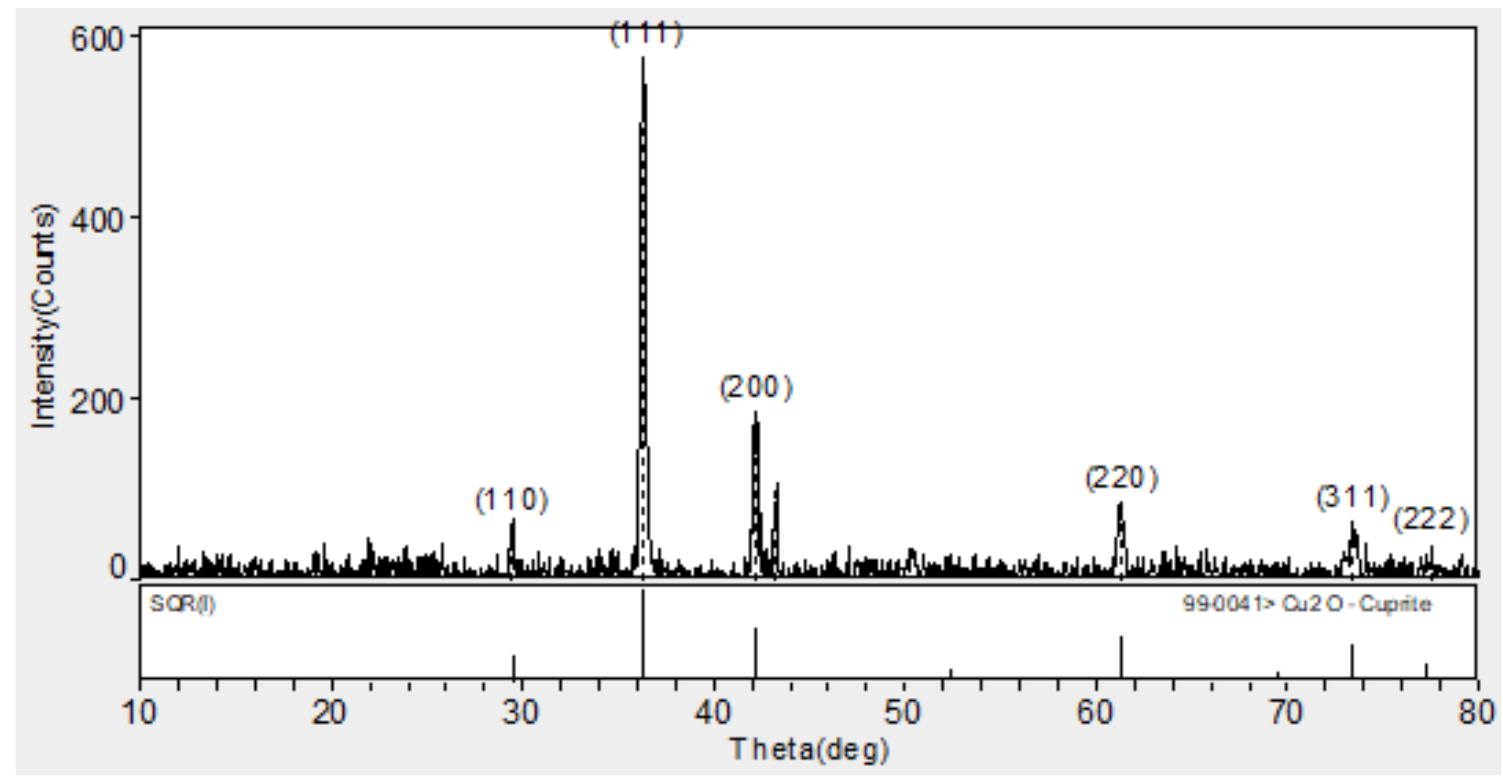

Figure (3). XRD result of copper nanopowder of $0.5 \mathrm{M} \mathrm{CuSO}_{4} 5 \mathrm{H}_{2} \mathrm{O}$ electrolyte solution .

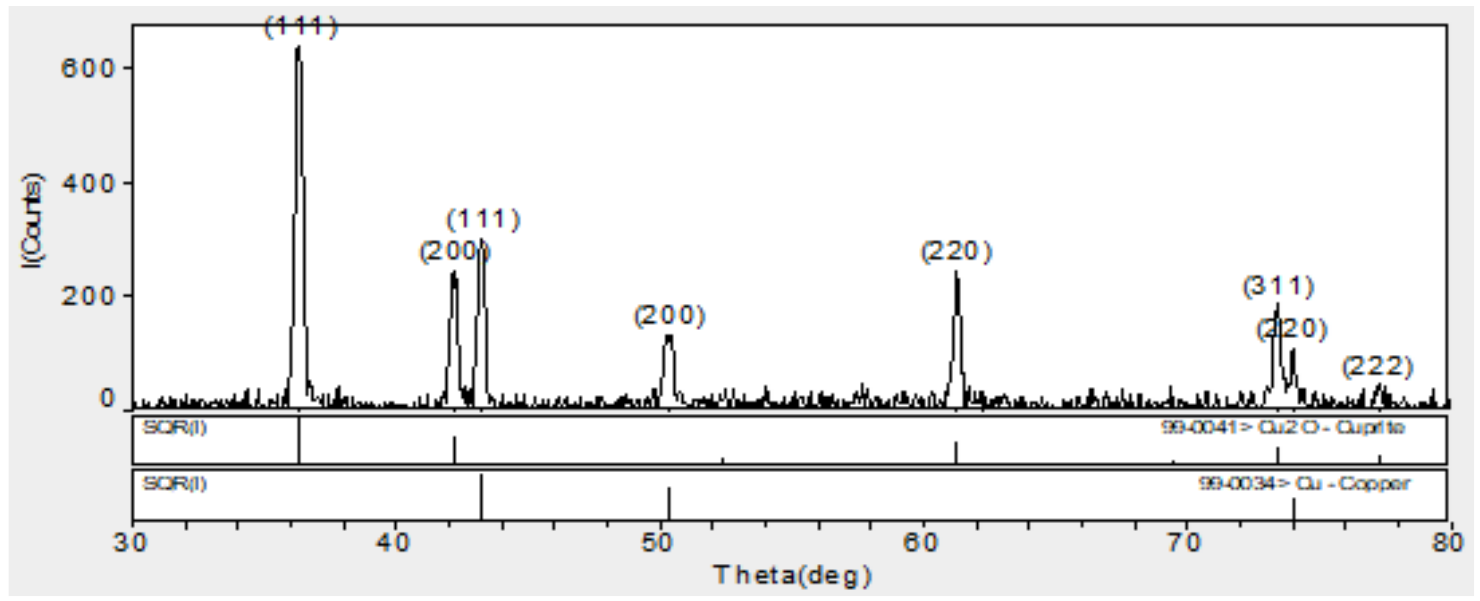

Figure (4). Nanopowser of $1 \mathrm{M} \mathrm{CuSO}_{4} 5 \mathrm{H}_{2} \mathrm{O}$ electrolyte solution.

The XRD patterns of nanopwder that was obtained from using $1 \mathrm{M} \mathrm{Cu}\left(\mathrm{NO}_{3}\right)_{2} .5 \mathrm{H}_{2} \mathrm{O}$ as electrolyte solution is quite similar to that of $1 \mathrm{M} \mathrm{CuSO}_{4} .5 \mathrm{H}_{2} \mathrm{O}$ as shown in Figure (5). The peaks at $2 \theta$ of 36.392, 42.248, 52.391, $61.303,73.494$, and $77.265^{\circ}$ correspond to (110), (111), (200), (211), (220), (311), and (222) crystal planes of 
$\mathrm{Cu}_{2} \mathrm{O}$ and the peaks at $2 \theta$ of $43.257,50.433$, and $74.090^{\circ}$ correspond to (111), (200), and (220) crystal planes of $\mathrm{Cu}$. The value of the average crystallite size was $25 \mathrm{~nm}$.

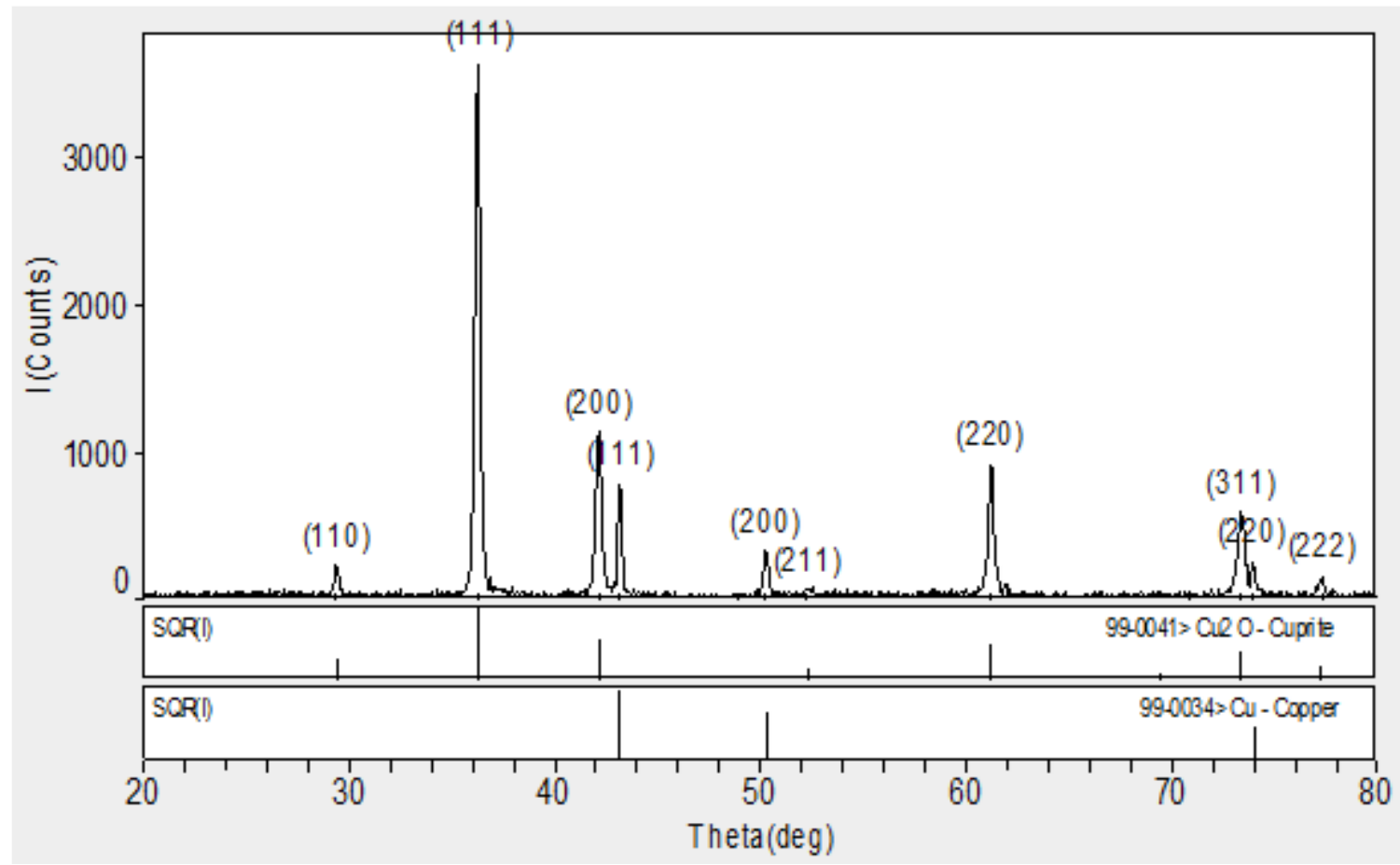

Figure (5). Copper nanopowder of $1 \mathrm{M} \mathrm{Cu}\left(\mathrm{NO}_{3}\right)_{2} 5 \mathrm{H}_{2} \mathrm{O}$ electrolyte solution.

Two types of antioxidants thiourea and ascorbic acid were added to the electrolyte solutions to prevent the oxidation of copper nanopowder during the process of electrochemical analysis. The XRD patterns of nanopowder that obtained after adding $0.02 \%$ of thiourea to the $1 \mathrm{M} \mathrm{Cu}\left(\mathrm{NO}_{3}\right)_{2} 5 \mathrm{H} 2 \mathrm{O}$ electrolyte solution are shown in Figure (6). The peaks were at $2 \theta$ of 12.228, 16.104, 29.025, 35.899, 41.852, 42.702, 49.9, 51.865, $52.592,53.012,60.95,66.901,73.3$, and $76.942^{\circ}$. However, the peaks at $2 \theta$ of $29.025,53.012,60.95$, and $73.3^{\circ}$ corresponding to (101), (200), (104), and (114), respectively, which indicating of $\mathrm{Cu}_{2} \mathrm{~S}$ and the results confirm the impurity of the sample. The $2 \theta$ peaks at $42.702,49.9$ and $73.3^{\circ}$ demonstrate for a shift in $2 \theta$ angles of phases of copper and copper oxide nanopowder. It could be the mixed nanopowder of cover with $\mathrm{Cu}_{2} \mathrm{~S}$ and thiourea [12]. The calculated crystals' size is $16 \mathrm{~nm}$. In spite of the small size that was gotten from this treatment. The impurity of the sample made it unsuitable process to produce copper nanopowder. 


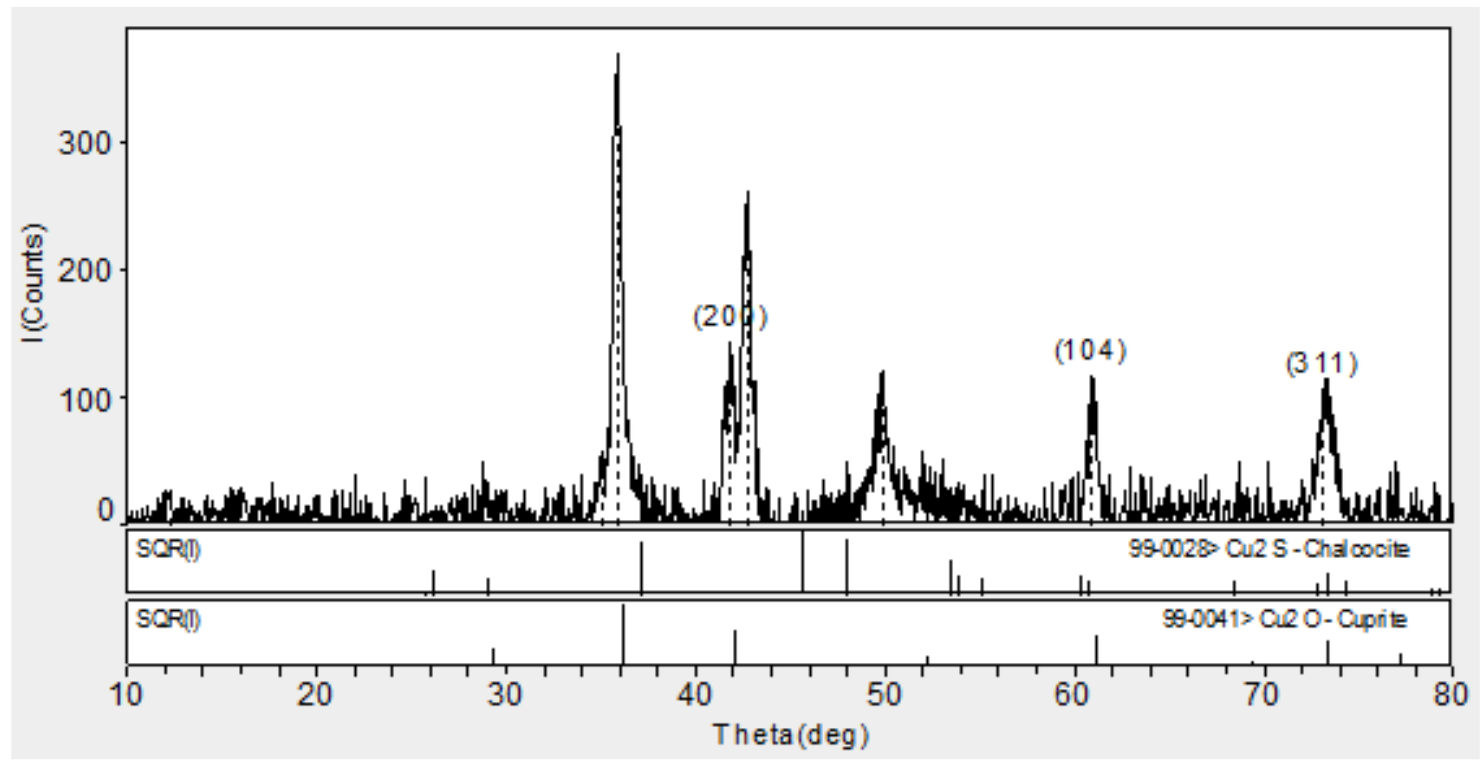

Figure (6). Copper nanopowser of $0.02 \%$ thiourea with1 $\mathrm{M} \mathrm{CuSO}_{4} .5 \mathrm{H}_{2} \mathrm{O}$ electrolyte solution.

The nanopowder that obtained from electrolytic method using of two different electrolyte solutions was treated with $2 \%$ ascorbic acid as illustrated in Figure (7). The results of XRD show no peaks of impurities or reflections of $2 \theta$ angles. The peaks at $43.160,50.295$, and $73.952^{\circ}$ are attributed to the (111), (200) and (220) planes. These peaks are characteristics of the face-centered cubic (FCC) structure of metallic copper and no diffractions of the crystallographic impurities are found. In fact, there are energetically distinct sites on each crystallographic facet, which is based on the density of an atom. The highest atom density facets for copper nanopowder are recognized to be highly reactive (111). For a phase center materials have a high intense peak at (111) reflection that (hkl) all odd or all even. Peaks of diffraction correspond well with ICDD cards No. 99-0034 are observed [5].

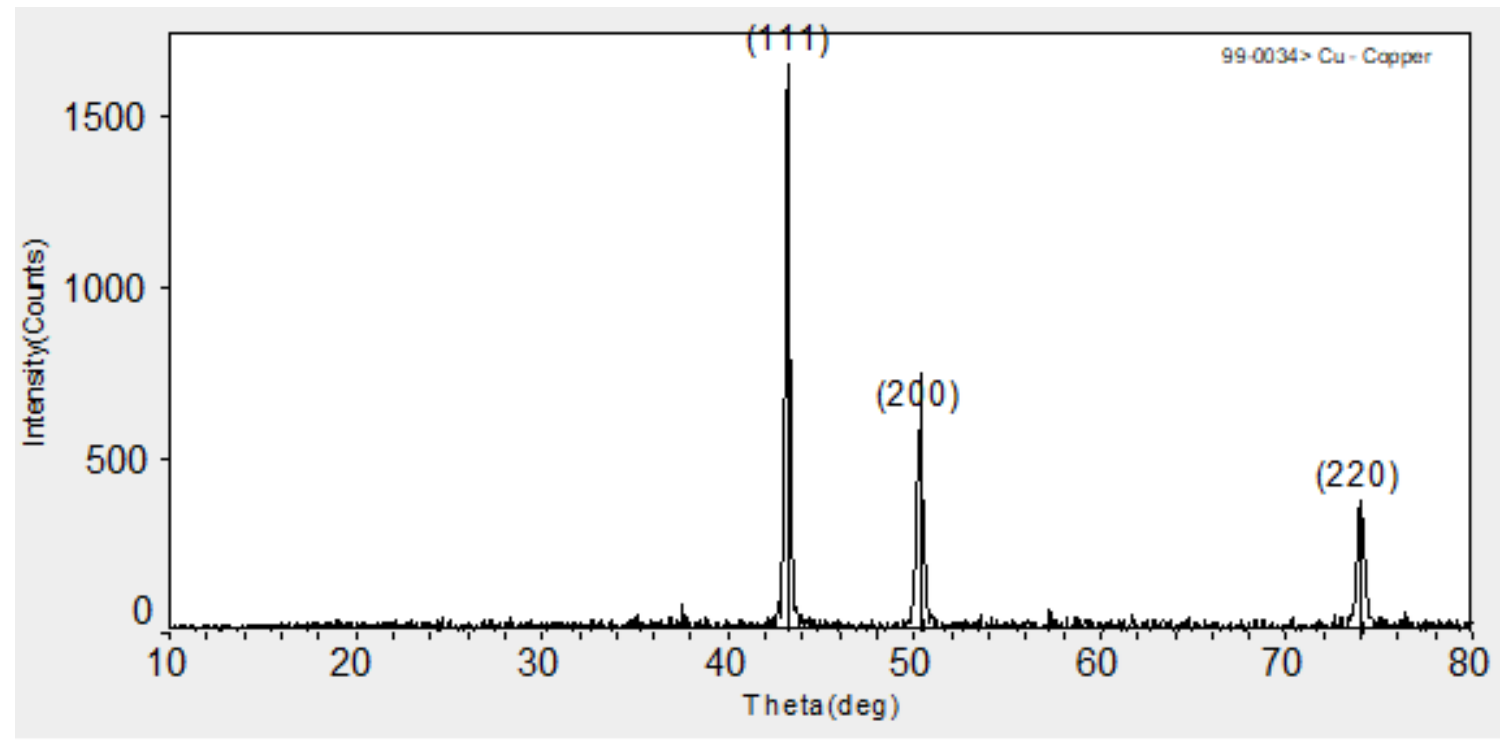

Figure (7). Copper nanopowder of $1 \mathrm{M} \mathrm{Cu}\left(\mathrm{NO}_{3}\right)_{2} 5 \mathrm{H}_{2} \mathrm{O}$ electrolyte solution after treated with $2 \%$ ascorbic acid.

The results of SEM for synthesized copper nanopowder which is characterized morphologically and nanostructurally are shown in Figure (8). SEM image indicates the dot shaped and highly crystalline copper nanopwoder and the appearance of individual particles is spherical in shape. The size of the Cu nanopowder was measured by image $\mathrm{J}$ software which was approximately $18 \mathrm{~nm}$. However, in lower resolution, we can notice 
some large particles, which could be accumulated from forming Van Der Waals clusters of smaller particles [5].

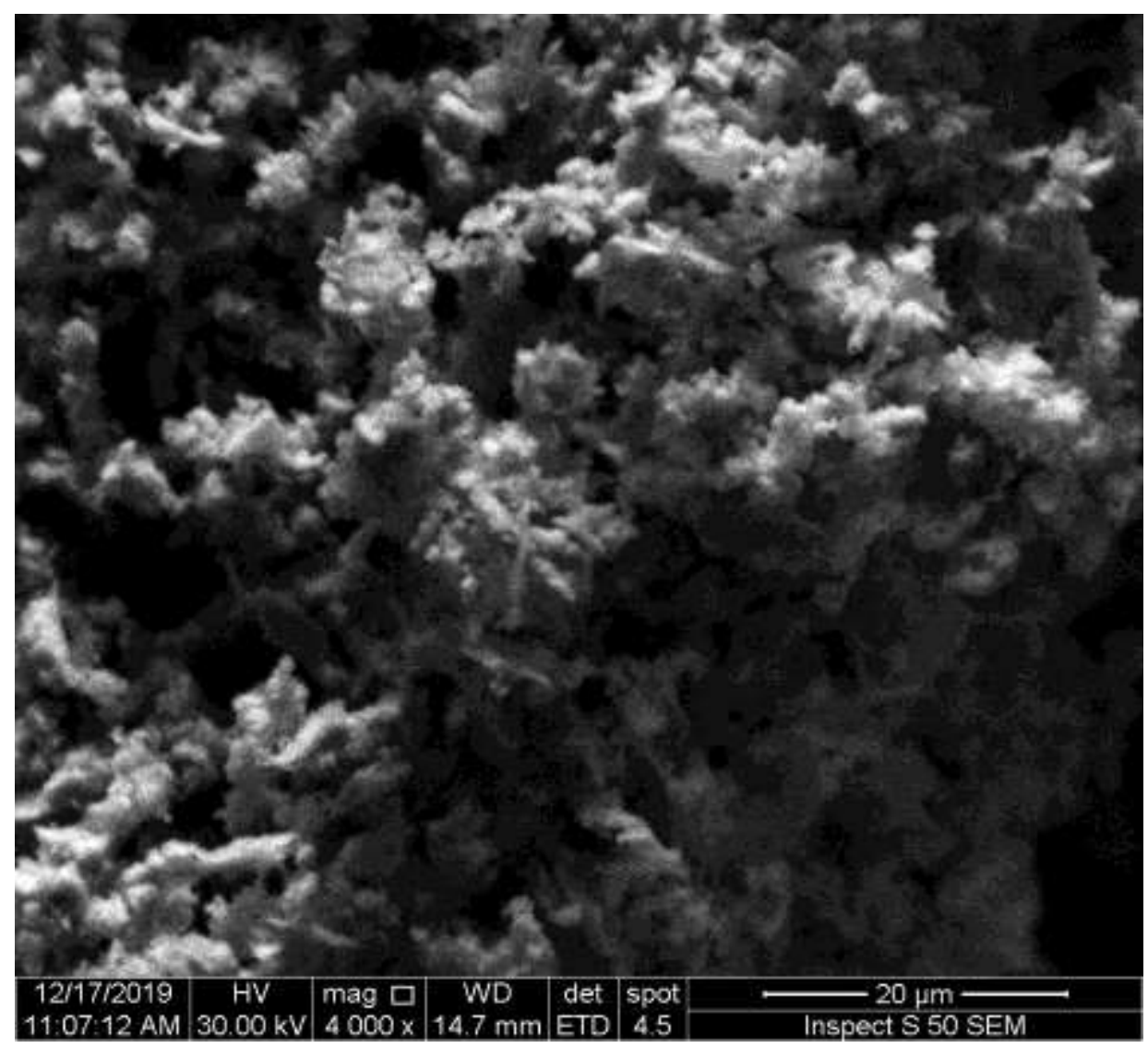

Figure (8). SEM micrographic image of synthesized copper nanopowder.

The sample was determined by Energy Dispersive Spectrum (EDS) measurement. The EDS indicates that the major chemical element of synthesized copper nanopowder is copper with a small amount of $\mathrm{C}$ and $\mathrm{O}$. No impurity elements were detected as illustrated in Figure (9). 


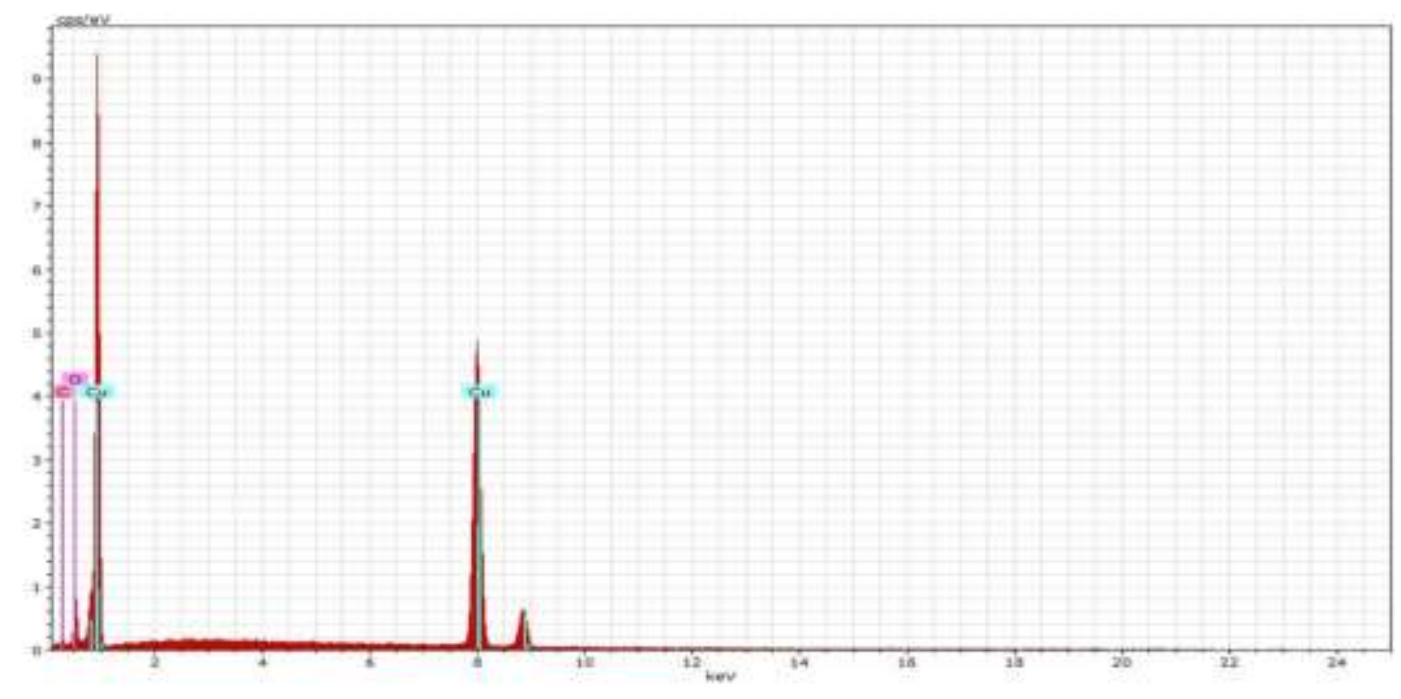

\begin{tabular}{|c|c|c|c|c|c|c|}
\hline Fel. & 202 & Sonclana & $\begin{array}{l}\text { urn. C } \\
\text { [we. \& ] }\end{array}$ & $\begin{array}{l}\text { nom. } \\
\text { [Wt. } 8 \text { ] }\end{array}$ & $\begin{array}{l}\text { Atam. o Frroo } \\
\text { [at. s] }\end{array}$ & $\begin{array}{l}\text { (1. Sigma) } \\
\text { [wt. } 8 \text { ] }\end{array}$ \\
\hline$\infty$ & 29 & K-serins & 52.51 & 74.39 & 39.19 & 1.47 \\
\hline 0 & a & $K-\sec 10 a$ & 10.72 & 15.18 & 31.76 & 2.89 \\
\hline c & 6 & K-serites & 7.36 & 10.42 & 29.05 & 3.31 \\
\hline
\end{tabular}

Figure (9). EDS Spectrum of copper nanopowder.

\section{Conclusions}

Electrochemical method is considered as an efficient, cost effective, and environmentally friendly process. The method of synthesizing has a noticeable effect on the particle structure characteristics such as size and morphology. It can conclude the shape and size of copper and purity of the nanopowder are affected by the concentration of electrolyte solution, current density, and the addition or treatment of the produced powder. The nanopowders were synthesized using two different salts (copper:sulfate and nitrate aqueous solutions). The synthesized nanopowder was a mixed of nanocopper and nanocopper oxide with particles size of 41 and $25 \mathrm{~nm}$, respectively. The nanopowder that treated with $2 \%$ ascorbic acid was high purity spherical shape with a size of around $18 \mathrm{~nm}$.

\section{References}

[1] R. K. Nekouei, F. Rashchi, and A. Ravanbakhsh, "Copper nanopowder synthesis by electrolysis method in nitrate and sulfate solutions," Powder technology, vol. 250, pp. 91-96, 2013.

[2] M. Jayandran, M. Haneefa, and V. Balasubramanian, "Green synthesis, characterization and antimicrobial activity studies of curcuminaniline biofunctionalized copper oxide nanoparticles," Indian Journal of Science and Technology, vol. 9, pp. 1-9, 2016.

[3] J. Ramyadevi, K. Jeyasubramanian, A. Marikani, G. Rajakumar, A. A. Rahuman, T. Santhoshkumar, et al., "Copper nanoparticles synthesized by polyol process used to control hematophagous parasites," Parasitology research, vol. 109, pp. 1403-1415, 2011.

[4] S. Wahyudi, S. Soepriyanto, and M. Mubarok, "Synthesis and Applications of Copper Nanopowder-A Review," in IOP Conference Series: Materials Science and Engineering, 2018, p. 012014. 
[5] T. Theivasanthi and M. Alagar, "Nano sized copper particles by electrolytic synthesis and characterizations," International Journal of Physical Sciences, vol. 6, pp. 3662-3671, 2011.

[6] M. T. El-Saadony, A. El-Hack, E. Mohamed, A. E. Taha, M. M. Fouda, J. S. Ajarem, et al., "Ecofriendly synthesis and insecticidal application of copper nanoparticles against the storage pest Tribolium castaneum," Nanomaterials, vol. 10, p. 587, 2020.

[7] L. Avramović, V. M. Maksimović, Z. Baščarević, N. Ignjatović, M. Bugarin, R. Marković, et al., "Influence of the Shape of Copper Powder Particles on the Crystal Structure and Some Decisive Characteristics of the Metal Powders," Metals, vol. 9, p. 56, 2019.

[8] M. I. Din and R. Rehan, "Synthesis, characterization, and applications of copper nanoparticles," Analytical Letters, vol. 50, pp. 50-62, 2017.

[9] EmanAlzahrani and R. A. Ahmed, "Synthesis of copper nanoparticles with various sizes and shapes: application as a superior non-enzymatic sensor and antibacterial agent," International Journal of Electrochemical Science, vol. 11, pp. 4712-4723, 2016.

[10]N. D. Nikolić, L. Avramović, E. R. Ivanović, V. M. Maksimović, Z. Baščarević, and N. Ignjatović, "Comparative morphological and crystallographic analysis of copper powders obtained under different electrolysis conditions," Transactions of Nonferrous Metals Society of China, vol. 29, pp. 1275-1284, 2019.

[11]H. D. Omar, "The analysis of copper-iron metallic mixture by means of XRD and XRF," International Letters of Chemistry, Physics and Astronomy, vol. 64, p. 130, 2016.

[12]P. Hasanzade, A. Akbaripour, M. Falaki, E. Tabesh, and S. Soleymani, "Effect of additives of cellulose and thiourea on synthesis of nano copper powders via pulse electrolysis method," International Journal Of Advanced Biotechnology And Research, vol. 8, pp. 1574-1581, 2017. 